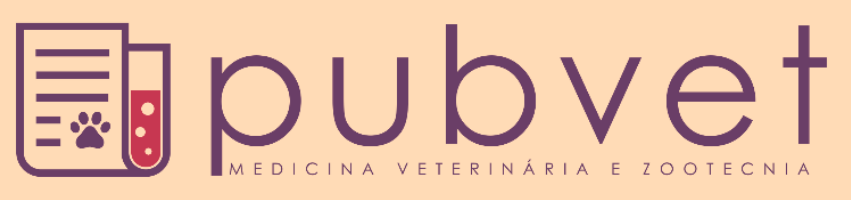

https://doi.org/10.31533/pubvet.v13n8a392.1-6

\title{
Avaliação da reutilização de cama de frango sobre a condenação de carcaças por colibacilose
}

\author{
Gabrielli Stefaninni Santiago $^{1 * \bullet}$, Juliana Franco Passarini ${ }^{2}$, Juliana Aparecida Cerqueira ${ }^{30}$, \\ Humberto Vinícius Faria da Cunha ${ }^{4}$
}

${ }^{I}$ Médica Veterinária, MSc, DSc, Discente de Pós-Graduação Lato Sensu Defesa Sanitária e Tecnologia e Inspeção de Produtos de Origem Animal com Ênfase em Legislação, IFOPE. ${ }^{2}$ Médica Veterinária, Ministério da Agricultura, Pecuária e Abastecimento, Brasil; ${ }^{3}$ Médica Veterinária, MSc, Ministério da Agricultura, Pecuária e Abastecimento, Brasil. ${ }^{4}$ Médico Veterinário, MSc, Docente de PósGraduação Lato Sensu Defesa Sanitária e Tecnologia e Inspeção de Produtos de Origem Animal com Ênfase em Legislação, IFOPE *Autor para correspondência, E-mail: gabriellissantiago@outlook.com

Resumo. O objetivo desse trabalho foi avaliar a influência do reuso da cama de frango sobre a condenação de carcaças de frangos em dois abatedouros sob inspeção federal, no Estado de São Paulo, que obtêm aves de granjas com protocolos de reuso de cama diferentes. O Brasil é um grande produtor e exportador de carne de frango e há muitas perdas na cadeia produtiva, o que poderia resultar em uma maior produtividade se não fossem os problemas nesse processo. O manejo da cama de frangos é importante para a qualidade final das carcaças e está associada a grande parte das patologias encontradas nas aves, como a colibacilose. O abatedouro " $\mathrm{A}$ " abate aves provenientes de granjas que utilizam a cama por no máximo seis vezes, já o abatedouro " $\mathrm{B}$ " utiliza mais de seis vezes a mesma cama, ambos utilizam a cama após sua reviragem e fermentação. A condenação por essa patologia foi nula no abatedouro cujo reuso é limitado, enquanto no abatedouro "B" foi de $0,06 \%$, demonstrando uma relação entre o número de vezes de utilização da cama e a patologia em estudo. Assim, conclui-se que o manejo da cama de frango pode ser o responsável pelas perdas de carcaças por colibacilose na indústria aviária.

Palavras chave: cama de frango, Escherichia coli, perdas econômicas, sanidade animal, segurança de alimentos

\section{Evaluation of the reuse of poultry litter on the carcass condemnated due to colibacillosis}

\begin{abstract}
The objective of this work was to evaluate the influence of poultry litter reuse on the condemnation of chicken carcasses in two slaughterhouses under federal inspection in the State of São Paulo, which obtain poultry from farms with different bed reuse protocols. Brazil is a major producer and exporter of chicken meat and there are many losses in the production chain, which could result in higher productivity if there are not problems in that process. The management of poultry litter is important for the final quality of the carcasses and is associated with most of the pathologies found in broilers, such as colibacillosis. Do not observed condemnation by colibacillosis in the slaughtering " $A$ " that farms reuse the chicken litter for a maximum of six times. But in the slaughterhouse " $\mathrm{B}$ " the carcasses rejection was $0.06 \%$ and the chickens were coming from farms that reuse the material for more than six times. Both farms reuse the chicken litter after turning and fermentation protocols. These results demonstrate a relation between the number of times the material is used and the pathology studied. Thus, the management of chicken litter can be responsible for the losses of carcasses by colibacillosis in the poultry industry.
\end{abstract}

Key words: animal health, chicken litter, economic losses, Escherichia coli, food safety 


\section{Evaluación de la reutilización de la gallinaza sobre la condenación de canales por colibacilosis}

Resumen. El objetivo de este trabajo fue evaluar la influencia de la reutilización de la gallinaza en la condena de las canales de pollos en dos mataderos bajo inspección federal en el estado de São Paulo, que obtienen aves de granjas con diferentes protocolos de reutilización de camas. Brasil es un importante productor y exportador de carne de pollo y hay muchas pérdidas en la cadena de producción, lo que podría resultar en una mayor productividad, si no hubiera problemas de ese proceso. El manejo de la gallinaza es importante para la calidad final de las canales y se asocia con la mayoría de las patologías encontradas en las aves, como la colibacilosis. El matadero "A" sacrifica aves de granjas que usan la cama un máximo de seis veces, ya el matadero "B" usa más de seis veces la misma cama, ambas usan la cama después de su giro y fermentación. La condena por esta patología fue nula en el matadero cuya reutilización es limitada, mientras que en el matadero "B" fue del 0,06\%, lo que muestra una relación entre el número de veces que se usa la cama y la patología en estudio. Por lo tanto, se concluye que el manejo de la gallinaza puede ser responsable por las pérdidas de canales por colibacilosis en la industria avícola.

Palabras clave: cama de pollo, Escherichia coli, pérdidas económicas, sanidad animal, seguridad alimentaria

\section{Introdução}

A colibacilose se caracteriza por uma síndrome complexa na qual se observam lesões em órgãos, como sacos aéreos, fígado (peri-hepatite) e coração (pericardite), levando à rejeição de carcaças de frango no abatedouro. Essa doença está relacionada principalmente a cepas de Escherichia coli APEC (Avian Pathogenic Escherichia coli), embora outros patótipos de E. coli possam causar a doença nas aves e serem transmitidas ao consumidor. APEC não causa doença em humanos, mas pode ser responsável pela transferência de genes de virulência e resistência entre bactérias, que é um problema atual e muito discutido sobre o aspecto da saúde pública (Briñas et al., 2002; Dorado-García et al., 2017; Hiroi et al., 2011; Huijbers et al., 2016; Ozaki et al., 2017).

Segundo estudos, a qualidade da cama utilizada na granja influencia diretamente a sanidade do lote aviário e a qualidade da carcaça obtida no abatedouro (Brito et al., 2016; Campos et al., 2018; Dunlop et al., 2016). A quantidade e tipos de microrganismos presentes nesse material são influenciados pelo número de reusos, manejo do material após a saída do lote, como a fermentação, densidade de aves no galpão e período de vazio sanitário (Garcia et al., 2013; Santos et al., 2012). No Brasil, não existe uma legislação que defina o número máximo de reusos da cama de frango, mas esse procedimento deve ser definido pelo estabelecimento criador de frango e constar em seu Programa de Autocontrole (PAC) (Brasil, 2017).

Esse trabalho tem como objetivo avaliar se há diferença de número de carcaças condenadas devido à colibacilose entre aves criadas em sistema com e sem número máximo de uso de cama nos galpões da granja.

\section{Materiais e métodos}

Selecionaram-se dois abatedouros sob Inspeção Federal, do Estado de São Paulo, os quais recebem frangos provenientes de granjas com diferentes manejos de cama. $\mathrm{O}$ abatedouro A recebe frangos que são criados em cama reutilizada por até seis vezes, ou seja, até seis lotes de frangos crescem sobre o mesmo material, sendo feita a reviragem e fermentação da cama entre um uso e outro. Os frangos recebidos pelo abatedouro B são criados em cama utilizada em mais de seis lotes de frangos. O material utilizado para a cama dos frangos abatidos em ambos os abatedouros é pó de serragem e os abatedouros comercializam os produtos para o mercado nacional e internacional. Os dados referentes à condenação de carcaças apresentando colibacilose nos abatedouros A e B foram coletados por dois anos, 2017 e 2018, para verificar a influência do número de reutilizações da cama sobre a ocorrência de colibacilose nos lotes de aves. 


\section{Resultados e discussão}

Os sinais de colibacilose em carcaças de frangos foram observados nas linhas de inspeção de carcaças dos abatedouros A e B, como ocorre normalmente na rotina de abate (Figura 1). O número de carcaças condenadas parcial e totalmente no abatedouro $\mathrm{A}$ devido à ocorrência de colibacilose foi de $0,0 \%$ (0/3.359.168). A mesma doença foi detectada em 114.032 carcaças do abatedouro B, sendo todas elas condenadas, de acordo com o exposto na tabela 1. Isso acarretou 2,3\% (114.032/4.871.522) de perdas relacionadas à colibacilose.

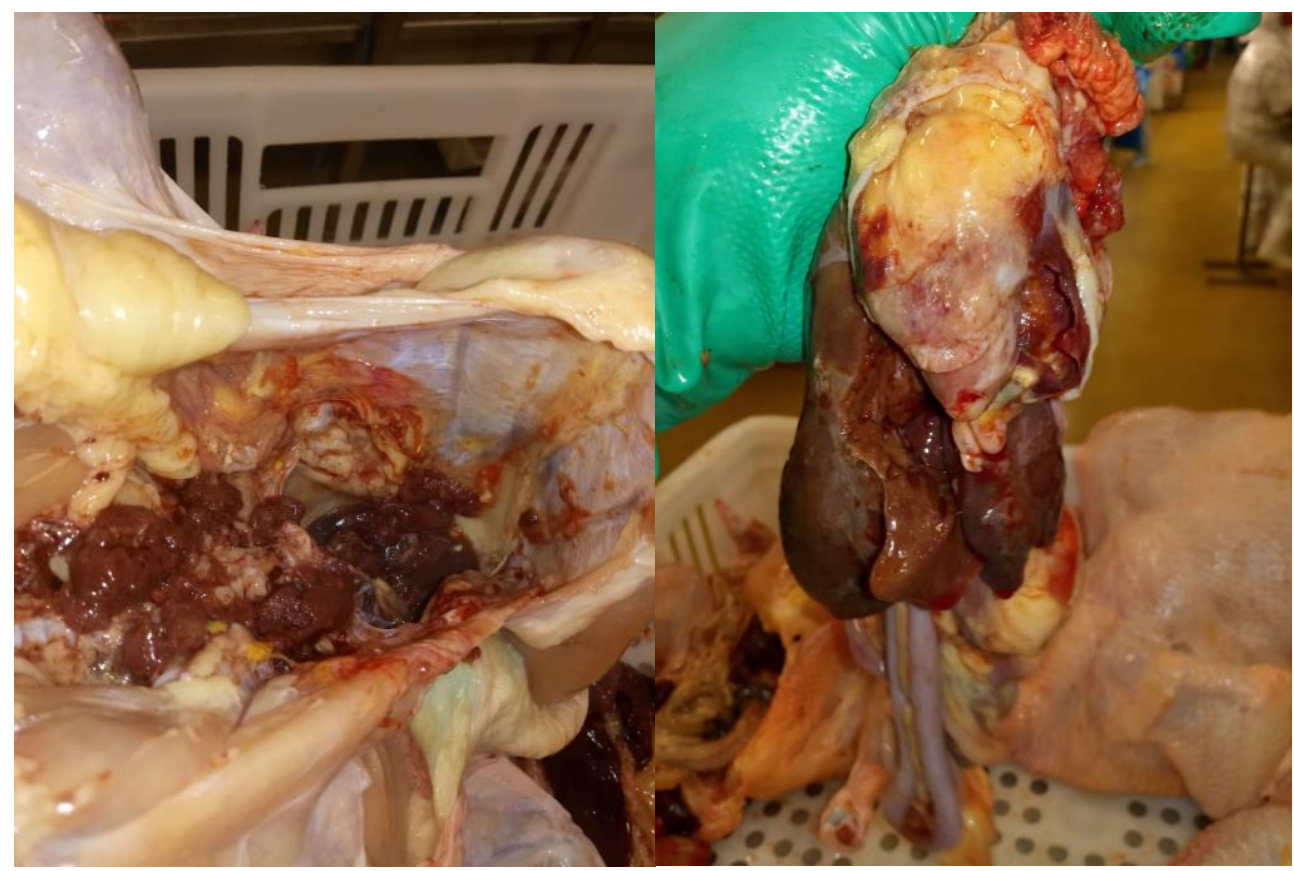

Figura 1. Carcaça condenada na linha de inspeção do abatedouro B devido à colibacilose. A foto à esquerda mostra uma carcaça ainda com os órgãos em seu interior, condenada por colibacilose. Foto à direita mostra fígado e coração com sinais sugestivos de colibacilose.

Ambos os abatedouros recebem animais provenientes de granjas com manejo de cama semelhante. Esse manejo inclui passagem de vassoura de fogo na cama após a saída do lote, lonamento do material e vazio sanitário que varia de 18 a 21 dias, dependendo se há ou não isolamento de Salmonella no lote criado. Algumas granjas são climatizadas, outras não. Nas climatizadas, a densidade populacional é de 13 aves $/ \mathrm{m}^{2}$ (metro quadrado) e naquelas não climatizadas, a densidade é de 12 aves/ $\mathrm{m}^{2}$.

Com relação à reutilização das camas pelas granjas, os protocolos são diferentes. O abatedouro $\mathrm{A}$ recebe os frangos de granjas que seguem PAC rigorosos com relação à reutilização das camas para lotes de aves diferentes. Nesse caso, o uso é limitado a, no máximo, seis vezes. Após isso, a cama de frango é utilizada para outras finalidades, mas não entrando em contato direto com as aves criadas no estabelecimento.

Tabela 1. Carcaças condenadas por colibacilose e o somatório das condenações, frangos abatidos e percentuais de carcaças condenadas por colibacilose nos abatedouros avaliados neste estudo

\begin{tabular}{lcccccc}
\hline \multirow{2}{*}{ Abatedouro } & \multicolumn{2}{c}{ Condenações } & \multirow{2}{*}{$\mathrm{c} / \mathrm{t}(\%)$} & \multirow{2}{*}{ Frangos abatidos (f) } & $\mathrm{c} / \mathrm{f}(\%)$ \\
\cline { 2 - 3 } & Colibacilose $(\mathrm{c})$ & Total $(\mathrm{t})$ & & & & \\
\hline $\mathrm{A}$ & 0 & 3.359 .168 & 0 & 62.318 .737 & 0 \\
$\mathrm{~B}$ & 114.032 & 4.871 .522 & 2,3 & 195.289 .361 & 0,06 \\
\hline
\end{tabular}

As aves adquiridas pelo abatedouro B são provenientes de estabelecimentos comerciais de criação no qual o PAC não define o número máximo de usos para a cama de frangos. Isso pode ser considerado um ponto crítico na cadeia de produção de carne de frango, pois o material da cama possui características que colaboram para a manutenção de micro-organismos e também para sua multiplicação e disseminação no ambiente (Campos et al., 2018; Oliveira \& Godoi, 2010). Embora o percentual de 
carcaças condenadas por colibacilose no abatedouro B seja baixo, comparado ao volume total de animais abatidos (0,06\% - 114.032/195.289.361 - tabela 1), esse dado demonstra que o manejo adequado da cama pode aumentar a produtividade das granjas. $\mathrm{O}$ mundo vem buscando por técnicas para aumentar a produção e a produtividade de alimentos para acompanhar o crescimento da população humana (Casagrande et al., 2017).

A colibacilose só é detectada no momento da inspeção, mas a infecção leva os lotes acometidos a terem uma baixa conversão alimentar, consequentemente as aves apresentam-se pequenas e com baixo peso corporal. Em muitos estabelecimentos criadores, essa doença acomete vários lotes que são condenados no abatedouro (Oliveira \& Carvalho, 2002).

Escherichia coli é o agente que ocasiona colibacilose e sua entrada no organismo da ave está associada à inalação e à ingestão dessa bactéria que contamina o ambiente de criação. Após entrar no organismo do frango, ela pode ocasionar infecção localizada, como é o caso de focos no fígado, ou então se disseminar para todo o organismo, evidenciando a infecção nos sacos aéreos, coração e fígado (Ozaki et al., 2017; Wang et al., 2017). No abatedouro, ambos os casos da infecção levam ao descarte da carcaça do frango pelo risco de transmissão do patógeno ao consumidor (Brasil, 1998; Santana et al., 2008).

Nas linhas de inspeção, o profissional visualiza as carcaças observando características de lesões sugestivas de infecção, mas não é realizado o isolamento do agente para o caso de colibacilose (Brasil, 2017). Estudos descrevem que doença é causada pela bactéria Escherichia coli e essa espécie é comumente relacionada à DTA, principalmente por alimentos de origem animal. Assim, independente do patótipo de E. coli, considera-se um risco para o consumidor (Forsythe, 2013).

A disseminação de Escherichia coli e de fatores de virulência e resistência são muito importantes para o ser humano, pois isso influencia diretamente na incidência de infecções causadas por essa espécie bacteriana e no tratamento dessas doenças. Há relatos de cepas de E. coli isoladas de frangos com colibacilose, na Argélia e no Brasil, contendo genes de virulência e de resistência aos antimicrobianos (Delicato et al., 2003). Isso é um problema muito discutido no contexto de saúde pública e tem sido tema de reuniões envolvendo a Organização Mundial de Saúde (OMS) e a Organização Mundial de Saúde Animal (OIE) (Dorado-García et al., 2017; Huijbers et al., 2016; Ozaki et al., 2017).

O Brasil foi considerado o segundo maior produtor e o maior exportador mundial de carne de frango em 2017. O Estado de São Paulo foi responsável por 9,32\% dos abates de aves. A produção avícola brasileira é organizada em um sistema integrado com parceria entre produtores e agroindústrias processadoras (ABPA, 2018). Os prejuízos por descarte de carcaças de aves nos abatedouros sob fiscalização federal no Estado de São Paulo, de 2006 a 2016, foi de R\$ 127,95 milhões (Ebling \& Basurco, 2016). A colibacilose aviária acarreta grandes perdas econômicas, a nível global. Na região Sul do Brasil, a colibacilose é a principal causa de condenação total de carcaças de frangos em abatedouros sob Serviço de Inspeção Federal (Casagrande et al., 2017; Maluta et al., 2014; Ozaki et al., 2017; Wang et al., 2017). Uma forma de diminuir o prejuízo é melhorar a qualidade das aves que serão abatidas e servirão como alimento para o ser humano, uma vez que as condenações causam problemas para todo o cenário de produção de frango. Assim, os PAC devem ser mais rigorosos quanto ao reuso de cama de frango na granja.

O PAC é um programa no qual a empresa estabelece normas internas para o seu bom funcionamento e garantia da qualidade de seus produtos. Atualmente, devido ao alto custo dos materiais utilizados para compor a cama, vem-se optando pela reutilização da cama. Embora alguns estabelecimentos definam o limite de seis lotes consecutivos criados sobre o mesmo material, muitos não definem isso no PAC, deixando a cargo do responsável pelo galpão avaliar a necessidade de descarte da cama. Nesse caso, a qualidade do material que está servindo de cama para os frangos criados naquele galpão fica comprometida, uma vez que não é possível determiná-la apenas com a observação do material (Campos et al., 2018; Oliveira \& Godoi, 2010).

Muitos trabalhos relatam que a reutilização da cama de frango ocasiona problemas sanitários nos lotes expostos a esse material, uma vez que lotes diferentes possuem microbiotas diferentes que podem ser disseminadas. Além disso, estudos demonstram que a quantidade de substâncias tóxicas na cama pode acarretar problemas respiratórios diretamente ou predispor infecções bacterianas (Castro, 2018; 
Oliveira \& Godoi, 2010). A cama de frango é um meio rico em matéria orgânica proveniente da alimentação e dos dejetos das aves. Isso viabiliza o crescimento e a multiplicação de micro-organismos, especialmente Escherichia coli, o agente causador da colibacilose (Campos et al., 2018; Castro, 2018).

Chinivasagam et al. (2016) demonstraram não haver influência direta da quantidade de reusos da cama e a concentração de Escherichia coli em cama de frango. Entretanto, outros trabalhos deverão ser realizados a fim de melhor elucidar se apenas limitar o número máximo de reutilização é suficiente para diminuir o número de carcaças condenadas por colibacilose ou se isso deve estar associado ao controle da fermentação e reviragem da cama, vazio sanitário e densidade de frangos por galpão.

\section{Conclusão}

O presente trabalho demonstrou que o reuso da cama de frango influencia diretamente o número de carcaças condenadas por causa de colibacilose. Assim, o limite de reusos pode ter sido responsável pela inexistência de condenações por essa doença, em um dos abatedouros avaliados.

\section{Referências bibliográficas}

ABPA, Associação Brasileira de Proteína Animal. Relatório anual de 2018. Disponível em:<http://abpa-br.com.br/storage/files/relatorio-anual-2018.pdf>. Acesso em: 29 de janeiro de 2019.

Brasil. 1998. Portaria $n^{\circ}$ 210, 10 de novembro de 1998. Ministério da Agricultura, Pecuária e Abastecimento. Brasília: DF.

Brasil. 2017. Decreto $n^{o}$ 9.013, 29 de março de 2017. Ministério da Agricultura, Pecuária e Abastecimento. Brasília: DF.

Briñas, L., Zarazaga, M., Sáenz, Y., Ruiz-Larrea, F. \& Torres, C. (2002). $\beta$-Lactamases in ampicillinresistant Escherichia coli isolates from foods, humans, and healthy animals. Antimicrobial Agents and Chemotherapy, 46(10):3156-3163.

Brito, D. A. P., Brito, D. R. B., Gomes, A. M. N., Cunha, A. d. S., Silva Filho, U. A. \& Pinheiro, A. A. (2016). Desempenho produtivo e rendimento de carcaça de frangos criados em diferentes materiais de cama aviária. Ciência Animal Brasileira, 17(2):192-197.

Campos, M. F. F. S., Teófilo, T. S., Chaves, D. P., Santos, A. C. G., Lopes, B. C. A., Bezerra, N. P. C. \& Torres, M. A. (2018). Identificação parasitológica da cama de frango reutilizada em uma granja avícola. Revista Brasileira de Ciência Veterinária, 25(1).

Casagrande, R. A., Machado, G., Guerra, P. R., Castro, L. A., Spanamberg, A., Silva, S. C., . . . Driemeier, D. (2017). Caracterização anatomopatológica e bacteriológica em frangos de corte condenados totalmente por colibacilose sob Serviço de Inspeção Federal. Pesquisa Veterinária Brasileira, 37(9):949-957.

Castro, C. M. (2018). Manejo da cama aviária e impactos na produção avícola. Anais do $19^{\circ}$ Simpósio Brasil Sul de Avicultura e 10 Brasil Sul Poultry Fair, 11-21.

Chinivasagam, H. N., Estella, W., Rodrigues, H., Mayer, D. G., Weyand, C., Tran, T., . . Diallo, I. (2016). On-farm Campylobacter and Escherichia coli in commercial broiler chickens: Re-used bedding does not influence Campylobacter emergence and levels across sequential farming cycles. Poultry Science, 95(5):1105-1115.

Delicato, E. R., Brito, B. G., Gaziri, L. C. J. \& Vidotto, M. C. (2003). Virulence-associated genes in Escherichia coli isolates from poultry with colibacillosis. Veterinary Microbiology, 94(2):97-103.

Dorado-García, A., Smid, J. H., Van Pelt, W., Bonten, M. J. M., Fluit, A. C., van den Bunt, G., . . . Veldman, K. T. (2017). Molecular relatedness of ESBL/AmpC-producing Escherichia coli from humans, animals, food and the environment: a pooled analysis. Journal of Antimicrobial Chemotherapy, 73(2):339-347.

Dunlop, M. W., McAuley, J., Blackall, P. J. \& Stuetz, R. M. (2016). Water activity of poultry litter: Relationship to moisture content during a grow-out. Journal of Environmental Management, 172201-206. 
Ebling, P. D. \& Basurco, V. (2016). Análise das perdas econômicas oriundas da condenação de carcaças nos principais estados brasileiros produtores de frangos de corte. Revista de Ciências Agroveterinárias e Alimentos, 11-11.

Forsythe, S. J. (2013). Microbiologia da segurança dos alimentos. Porto Alegre, Rio Grande do Sul, Brasil: Artmed.

Garcia, R. G., Paz, I. C. d. L. A., Caldara, F. R., Naas, I. A., Freitas, L. W., Borille, R., . . S Spindola, N. F. (2013). Alternativas para a composição de cama de frango. Agrarian, 6(19):81-89.

Hiroi, M., Harada, T., Kawamori, F., Takahashi, N., Kanda, T., Sugiyama, K., . . Ohashi, N. (2011). A survey of beta-lactamase-producing Escherichia coli in farm animals and raw retail meat in Shizuoka Prefecture, Japan. Japanese Journal of Infectious Diseases, 64(2):153-155.

Huijbers, P. M. C., Graat, E. A. M., van Hoek, A. H. A. M., Veenman, C., de Jong, M. C. M. \& van Duijkeren, E. (2016). Transmission dynamics of extended-spectrum $\beta$-lactamase and AmpC $\beta$ lactamase-producing Escherichia coli in a broiler flock without antibiotic use. Preventive Veterinary Medicine, 13112-19.

Maluta, R. P., Logue, C. M., Casas, M. R. T., Meng, T., Guastalli, E. A. L., Rojas, T. C. G., . . Nolan, L. K. (2014). Overlapped sequence types (STs) and serogroups of avian pathogenic (APEC) and human extra-intestinal pathogenic (ExPEC) Escherichia coli isolated in Brazil. PloS one, 9(8):e105016.

Oliveira, M. C. \& Carvalho, I. D. (2002). Rendimento e lesões em carcaça de frangos de corte criados em diferentes camas e densidades populacionais. Ciência e Agrotecnologia, 26(5):1076-1081.

Oliveira, M. C. \& Godoi, C. R. (2010). Tratamento da cama de frango sobre o desempenho das aves e qualidade da carcaça e da cama-Revisão de literatura. PUBVET, 4752-758.

Ozaki, H., Matsuoka, Y., Nakagawa, E. \& Murase, T. (2017). Characteristics of Escherichia coli isolated from broiler chickens with colibacillosis in commercial farms from a common hatchery. Poultry Science, 96(10):3717-3724.

Santana, Â. P., Murata, L. S., Freitas, C. G., Delphino, M. K. \& Pimentel, C. M. (2008). Causes of condemnation of carcasses from poultry in slaughterhouses located in State of Goiás, Brazil. Ciência Rural, 38(9):2587-2592.

Santos, M. J. B., Samay, A. M. A. T., Silva, D. A. T., Rabello, C. B.-V., Torres, T. R., Santos, P. A. \& Camelo, L. C. L. (2012). Manejo e Tratamento de cama durante a criação de aves. Revista Eletrônica Nutritime, 91801-1815.

Wang, S., Peng, Q., Jia, H. M., Zeng, X. F., Zhu, J. L., Hou, C. L., . . Qiao, S. Y. (2017). Prevention of Escherichia coli infection in broiler chickens with Lactobacillus plantarum B1. Poultry Science, 96(8):2576-2586.

Recebido: 14 de julho, 2019.

Aprovado: 9 de agosto, 2019.

Publicado: 16 de setembro, 2019.

Licenciamento: Este artigo é publicado na modalidade Acesso Aberto sob a licença Creative Commons Atribuição 4.0 (CC-BY 4.0), a qual permite uso irrestrito, distribuição, reprodução em qualquer meio, desde que o autor e a fonte sejam devidamente creditados. 